\title{
RESENHA
}

\section{ESTADO E VONTADE COLETIVA EM GRAMSCI}

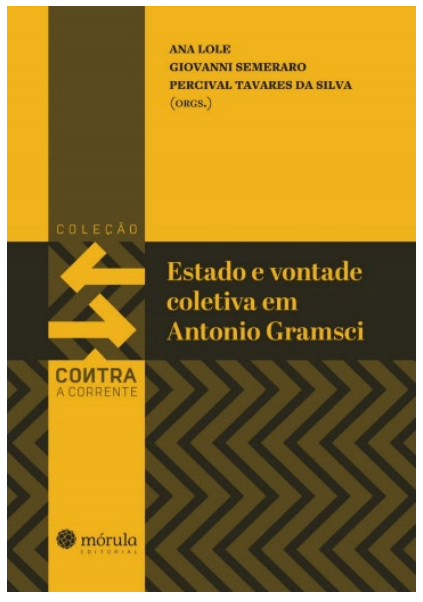

\author{
Por Antonio Michel de Jesus Miranda \\ Universidade Católica de Pernambuco \\ Recife, PE, Brasil
}

Dados catalográficos da obra LOLE, Ana; et al. (Orgs.). Estado e vontade coletiva em Gramsci. Rio de Janeiro: Mórula, 2018.

DOI: https://doi.org/10.22409/mov.v7i15.44512

Os manuscritos compilados no livro Estado e vontade coletiva em Gramsci foram organizados em dossiês temáticos e publicados, em 2017, em dois periódicos, quais sejam, Movimento-revista de educação, da Universidade Federal Fluminense, e O Social em Questão, da Pontifícia Universidade Católica (PUC-RJ), por ocasião de 80 anos da morte de Gramsci e 100 anos da Revolução de Outubro, organizados por Ana Lole, Giovanni Semeraro e Percival Tavares da Silva, todos doutores, docentes da Faculdade de Educação da Universidade Federal Fluminense (UFF) e membros do Núcleo de Estudos e Pesquisas em Filosofia, Política e Educação (NuFIPE/UFF).

Prefaciado por Rene José Trentin Silveira, professor da Faculdade de Educação da Universidade Estadual de Campinas (UINCAMP), o livro propõe reflexões em busca de uma democracia brasileira efetiva, a partir de onze capítulos e uma entrevista.

“O bloco histórico de Gramsci: estrutura, hegemonia e interações dialéticas", traduzido por Nicholas Davies, de Derek Boothman, professor da Universidade de Bolonha - Itália, indica nos Cadernos do Cárcere 10 e 13, 


\section{movim nto \\ revista de educação do \\ programa de pós-graduação \\ faculdade de educação \\ ano 7 - número 15 - 2020}

similaridades com os elementos do Bloco Histórico: uma dinâmica ligação entre todas as diferentes esferas da atividade humana (p. 25), um dinamismo temporal, comum à totalidade social - historicamente determinada - e ao bloco histórico, que para Gramsci, o conjunto destas relações dinâmicas e historicamente determinadas é o bloco histórico, cuja articulação interna se revela por aspectos da dialética e do conceito de "unidade dos opostos". Por fim, se reflete o léxico complexo de Gramsci, na "exploração da dialética" e, partindo da compreensão das forças unitárias entre teoria e prática, que movem historicamente o Bloco Histórico, o autor evoca um novo bloco, consciente destas forças, "sem contradições internas" (p. 39).

"Estado e sociedade civil e as relações entre o público e o privado no Brasil: reflexões a partir do pensamento de Antonio Gramsci”, Ana Lole, uma das organizadoras, e Inez Stampa, Doutora em Serviço Social, a partir do conceito gramsciano de Estado e sociedade civil, elucidam a lógica privativista. Para Hegel, sociedade civil é sistema econômico, jurídico e administrativo a interesse privado e não coletivo, cabendo ao Estado a universalização, que para Marx, é dificultada, sendo o Estado um "comitê executivo" da burguesia, a serviço de opressão, com pseudo interesse universal. De Marx e Hegel, chegase a Gramsci, definindo sociedade civil como "princípio organizador central da teoria socialista" (p. 46), o Estado é a unidade entre o civil e o político e para o alcance de uma emancipação humana e política (sua hegemonia), a arena é a sociedade civil, que diante da contemporaneidade, tem sido compreendida como "terceiro setor", por uma ótica privativista cunhada no capitalismo, contrária ao proposto por Gramsci.

"Gramsci e a Revolução de Outubro", tradução de Eduardo Granja Coutinho, de Guido Liguori, presidente da International Gramsci Society Itália, dá a Gramsci uma virada intelectual, a partir da Revolução, que a via cunhada num marxismo com o qual compactuava. Apresenta-se sua maturação intelectual, numa crítica de um pensamento maduro, dado num momento pós-Revolução, sem perder sua predileção à subjetividade, mas se assume marxista, num pensamento histórico-social, responsável por libertá-lo das "incrustações 


\section{movim nto \\ revista de educação do \\ programa de pós-graduação \\ faculdade de educação \\ ano 7 - número 15 - 2020}

idealistas e espiritualistas que o condicionavam" (p. 74). Já em cárcere, há uma nova maturação, denomina por "reforma intelectual e moral", responsável por revolucionar o conceito de revolução. A vontade revolucionária em Marx e Leni não fora substituída, mas para Gramsci, acrescida a necessidade da análise histórica e social minuciosa do terreno, o qual se desenvolve a luta de classes (p. 77).

\section{"Notas a partir da reflexão de Gramsci sobre a Revolução Russa",} Anita Helena Schlesener, Doutora em História, pontua a importância da Revolução para a história e democracia da classe russa trabalhadora de 1917, algo "que nós, pobres ocidentais domesticados pela ideologia burguesa, temos dificuldades em entender e explicar" (p. 84). Rebusca a contextura social, política e econômica, da época, capaz de eclodir tal movimento, encabeçado por Lenin e Trotsky, visto por Gramsci como autêntico, de interesses universais, dando aos trabalhadores o controle de suas vidas e trabalhos, um apoio do proletário revolucionário russo, a impulsionar, a revigorar, a emancipar a classe. Apropriando-se da revolução, Gramsci intensificava os incentivos ao movimento operário italiano, quanto a compreensão do conjunto de relações de forças de que fazem parte, para que saibam controlar aquilo que seus governantes thes impõem.

"Gramsci: educação e vontade coletiva", de Sérgio Miguel Tucartto, Doutor em Educação, discute educação e vontade coletiva em Gramsci, ao situar a educação à práxis e à vontade coletiva, como estratégia política pela hegemonia. A partir das relações dos operários em fábrica, o autor estabelece nexos para a compreensão da dimensão educativa, que pode ser clara a partir da participação do operário em associações culturais. Se discute educação e vontade coletiva, a partir da relação pedagógica na filosofia da práxis, "perpassada por um profundo historicismo, que capacita pensar a realidade como um movimento em direção ao futuro" (p. 109), uma educação no plano das ideologias, produto da realidade social que justifica e consolida o processo histórico. A partir da categorização de filosofia da práxis, da educação e das relações estabelecidas historicamente, a vontade transcende-se de si e passa 


\section{movim nto \\ revista de educação do \\ programa de pós-graduação \\ faculdade de educação \\ ano 7 - número 15 - 2020}

ao interesse comum, para uma vontade geral, compreendida por vontade coletiva.

“Desafios e tensões político-pedagógicas em Antonio Gramsci”, traduzido por Rodrigo de Sá Netto, de Sebastián Gómez, Doutor em Educação, traz Gramsci político-educativo, embasado na hegemonia, mesmo sem tê-lo por teoria pedagógica, se valendo dos escritos carcerários e dos juvenis. Desvela a escola como aparelho de hegemonia do Estado que, em nome de uma suposta democracia, condena a função de dirigentes a poucos e às massas, o instrumentalismo, eternizando a divisão social do trabalho. Explicita-se um tipo ideal de docente, nos desvelos sociais, averso à reprodução dos interesses dominantes. O sentido pedagógico em Gramsci, reside quando as relações político-educativas dinamizam outra concepção de mundo e rompem os aparelhos de hegemonia. Como Marx, Gramsci propunha uma escola omnilateral, única, de cultura geral humanística (desinteressada) e profissional (sem dualidades), sem restringir o acervo cultural.

"A práxis da formação política das classes populares”, de Percival Tavares da Silva, um dos organizadores, discute o político-educativo enquanto ação emancipatória, em suas experiências na Baixada Fluminense, Grande Rio - RJ. Rememora a militância da Igreja Popular de Nova Iguaçu, durante a Ditadura Militar e frente à lógica de mercado que adentrava o Brasil. Segundo o autor, a Diocese vem investindo em projetos de formação social (educação política popular), em parceria da Universidade Federal Fluminense - UFF, junto às lideranças comunitárias, a fim da apreensão de conhecimentos e na derrubada das práticas de cooptação adotadas pelas lideranças locais. Isso se dá pela Escola de Formação Política que tem por chave metodológica o "inventário da práxis e a cultura política dos inscritos, destacando-se pela articulação teórica e prática" (p. 155). O autor evoca Gramsci e Paulo Freire como base curricular da Escola de Formação, articulando o conhecimento universal da práxis e a cultura dos matriculados. traduzido por Eduardo Granja Coutinho, de Angelo D'Orsi, professor do 


\section{movim nto \\ revista de educação do \\ programa de pós-graduação \\ f a culdade de educ a ção \\ ano 7 - número 15 - 2020}

Dipartimento di Studi Storici/Universitá di Torino, Itália. E "As cinzas de Gramsci: Pasolini e a crise da vontade revolucionária”, de Eduardo Granja Coutinho, Doutor em Comunicação, discute-se o poema “As cinzas de Gramsci”, de Pasolini, em meio à crise intelectual italiana, sua relação com o comunismo e sua similitude quanto paixão e ideologia do poeta à teoria e ideologia do sardo. Compreende-se o poema na apreensão do contexto político-social da época, com a derrocada do desejo revolucionário antifascista e de um projeto político teoricamente fundado em Gramsci, bem como das paixões do poeta ao lançar de inúmeras metáforas, dentre elas, a de uma vontade coletiva reduzida as cinzas. O poema pessimista excita a superação de um marxismo mecanicista, otimista e acrítico. Os autores discorrem o desejo revolucionário que "sucumbe na tumba", mas que emerge no "populismo consciente" dos versos de Pasolini.

"Renascimento e reforma nos Quardeni del cárcere: a leitura política de Antonio Gramsci" de Marcos Del Roio, Doutor em Ciência Política, e Geraldo Magella Neres, Doutor em Ciências Sociais, vê o Renascimento e a Reforma como categorias importantes em Gramsci. Esclarece-se que embora os termos tenham fama histórica, estes assumem sentidos diferentes em Gramsci: o Renascimento, leva a uma cultura elitista formalmente elaborada, distante das massas. A Reforma, embora quando pouco elaborada, se vincula a interesses das massas. Confrontam-se estas categorias a fim de explicar o desenvolvimento histórico italiano, distante de uma vontade coletiva. Pois mesmo o Renascimento sendo progressista na Europa Ocidental, fora regressivo na Itália, que mesmo tendo forjado uma cultura ricamente elaborada, ainda assim, era distante das massas, de caráter puramente elitista. Por fim, é proposta uma dialética entre estas categorias como ideal para articular a cultural da massa, mas com uma alta intelectualidade.

"Gramsci e a religião: uma leitura a partir da América Latina”, Giovanni Semeraro, um dos organizadores da obra, traz, em Gramsci, a religião como anti-emancipatória, de imaginação humana a procurar respostas não encontradas na ciência e história. O socialismo, a partir do pensamento crítico coloca-a num patamar denunciativo: mantenedora das subalternidades das 


\section{movim nto \\ revista de educação do \\ programa de pós-graduação \\ faculdade de educação \\ ano 7 - número 15 - 2020}

classes. Gramsci rechaça a Igreja católica, tida como hegemônica e ideológica aliada à elite. Mas reconhecia a importância histórica e intelectual do cristianismo, que na modernidade, perdera a proximidade com o povo. Sobre a América Latina, é recobrada a "Teologia da Libertação" - inspirada no marxismo - que no seio destas terras, a partir de 1960, a Igreja anseia, luta e se organiza contra a hegemonia dominante. É retratado o contraste entre o que Gramsci propunha e este cristianismo que liberta, e que por vezes aspirações se entrelaçam.

Finalizando o livro: "A recepção de Gramsci na educação brasileira: entrevista com Demerval Saviani”, concedida a Percival Tavares da Silva, por e-mail e antes publicada na Movimento-revista de educação (2017), menciona Saviani como pioneiro de Gramsci nos estudos stricto sensu no Brasil. Muito embora, só o tenha conhecido pela iniciativa da primeira turma de doutorado em Educação da PUC-SP, o filósofo sardo é cativo em suas pesquisas e predileção pedagógica que contempla o materialismo-dialético-histórico, uma "teoria histórico-dialética" da educação: a pedagogia histórico-crítica, fundamentada no método da economia política de Marx, tendo a prática social (a situação concreta) como ponto de partida e ponto de chegada da prática educativa" ( $p$. 249). Saviani vê em Gramsci, a escola unitária como saída para a pedagogia esfacelada no Brasil.

A obra atinge aquilo que seus organizadores se dispuseram a fazer: instigar reflexões em busca de um Estado brasileiro erigido numa democracia do, e para o povo, já que, em nosso Brasil contemporâneo, as elites, em nome de uma falsa democracia, insistem em se dar por hegemônicas. Destaca-se a forma espetacular da distribuição dos capítulos ao longo da obra, de forma que um complementasse o outro e trouxesse ao seu leitor o deleite em cada discussão e o aquecer da chama que talvez tenha sido exatamente sentida pelos primeiros leitores de Pasolini em "As cinzas de Gramsci", que de fato Ihe tenha compreendido, assim como agora, por este livro, compreendo o Brasil, não envolto em cinzas. Isso quando em nosso peito, devido a tanto horror, já esfriava, congelado em nossos corações, o desejo de que nós, da massa, nos 


\section{movim nto \\ revista de educação do \\ programa de pós-graduação \\ faculdade de educação \\ ano 7 - número 15 - 2020}

apoderemos do saber intelectual, para que por ele possamos falir o projeto contrário às classes subalternas.

\section{Referência}

LOLE, Ana; et al. (Orgs.). Estado e vontade coletiva em Antonio Gramsci. Rio de Janeiro: Mórula, 2018.

\section{SOBRE O AUTOR}

ANTONIO MICHEL DE JESUS DE OLIVEIRA MIRANDA (Professor Surdo) é Mestre e doutorando em Ciências da Religião pela Universidade Católica de Pernambuco (UNICAP), professor do quadro efetivo das Secretarias Municipais de Buriti dos Lopes (PI) e de Tutoia (MA), coordenador de pós-graduação em Docência do Ensino Religioso da Faculdade de Ensino Superior da Parnaíba (FAESPA), membro do Grupo de Pesquisa Estudos Transdisciplinares em História Social, da Universidade Católica de Pernambuco (UNICAP).

E-mail: educadormichel@gmail.com 